\title{
UN LIBRO ALEMÁN DEL SIGLO XVII CON INFORMACIONES SOBRE MORISCOS EN ARGEL, TÚNEZ Y SALÉ
}

\author{
FrankMönkemöller*
}

En el año 1694 fue publicado en Hamburgo por el editor Thomas von Wiering un libro con el título: Schau=Platz barbarischer Sclaverey: Worauff unter Beschreibung der 4 vornehmsten Raub-Städte Als: Algiers, Thunis, Tripoli und Salee. Derselben Regierung / Raubereyen / Sitten / Gewohnheiten und andere seltsame Begebenheiten und Zufälle vorgestellt werden: Vornehmlich aber / die überaus grausahme Barbarische Leibes=Straffen / und das elende kümmerliche Leben / so die gefangenen Christen bey den Türcken und Unglaubigen leiden / außstehen und ertragen müssen. Historisch aufgeführet und mit vielen dazu dienlichen Kupfern erleutert. [Escenario de la esclavitud bárbara. Con la descripción de las cuatro ciudades del corso más destacadas, como son Argel, Túnez, Trípoli y Salé: sus gobiernos, robos, costumbres, hábitos y otros extraños sucesos y acontecimientos, pero especialmente los extremadamente crueles castigos corporales y la miserable vida que han de soportar y sufrir los cristianos cautivos con los turcos e infieles. Históricamente presentado y explicado con muchos grabados de utilidad]

En el prólogo, el mismo editor nos informa acerca de la paternidad de este texto:

"Es hat zwar der Wohlgelahrte Johann Frisch", Prediger zu Altona / vor einigen Jahren unter diesem Titel ein kleines Tractätlein heraus gegeben / wie er dann auch bey Lebzeiten noch jederzeit willens gewesen / es zu vermehren / und so dann auffs neue an das Tageslicht kommen zu lassen. Weil aber derselbe durch den zeitlichen Todt an

\footnotetext{
* $\quad$ Universität Bielefeld.
}

1. Johann Frisch nació en 1636 en Hamburgo y murió en 1692 en la misma ciudad. Estudió teología en Wittenberg y después ejerció como predicador en Altona. Fue autor de textos teológicos y devocionarios (Deulsches Literatur-Lexikon, V. Bd., Bern und München, $1978^{3}$, s.v.). 
diesem seine Färnehmen behindert / so hat man dennoch selbiges Tractätelein hie wieder mit einbringen / und das ander aus S. de Vries, Dappern, Busbeken, Traveniern und anderen unterschiedlichen Autoren, so von dieser Materie geschrieben zusammen tragen und ergrössern wollen" (p. 10).

[Publicó por cierto hace algunos años el muy docto Johann Frisch, predicador en Altona, un pequeño tratado con este título que siempre quiso aumentar en vida para poder sacarlo de nuevo a la luz del día. Pero la temprana muerte del mismo impidió su intento y por eso se ha querido incorporar aquí de nuevo este tratado, y compilarlo y agrandarlo con lo escrito acerca de esta materia por S. De Vries, Dappern, Busbeken², Traveniern y otros diferentes autores]

El libro contiene fundamentalmente una imagen pintoresca de la vida y de las penas padecidas por los esclavos cristianos en el Magreb. Se dirige de forma vehemente contra la esclavitud y por medio de crudos retratos de los castigos corporales infligidos a aquéllos intenta causar en el lector el rechazo correspondiente. Sin embargo encontramos junto con la descripción de los lugares centrales del corso, como Alger, Túnez y Salé, algunas informaciones sobre los moriscos que se han establecido en estas ciudades y que, sin mostrar grandes novedades, sí pueden resultar interesantes por tratarse de un testimonio contemporáneo dirigido a lectores de habla alemana. Ofrezco a continuación los fragmentos en cuestión (con el número de página entre paréntesis) más la traducción de cada uno de ellos entre corchetes:

"Die Einwohner der Stadt Algiers

(...) Die Tagarinen sind Mauri oder weie Mohren / nemblich diejene / welche Ao. 1609 wegen Auffruhrs aus Hispanien vertrieben / und mit grosser Menge alhie auffgenommen werden. Sie werden von den Türcken L'Andalusin genennent / und können weder Soldaten werden noch Pagen / das ist: Sold geniessen / noch zu einigem Ehren=Ambt steigen / sondern müssen sich allenthalben für die Türcken bücken; dannnenhero sie sich meistentheils auf die Kauffmanschaft legen/” (p. 36).

[Los habitantes de la ciudad de Argel

Los tagarinos son mauri o moros blancos, es decir, aquéllos que fueron expulsados en el año 1609 de España por rebelión y aquí recibidos en gran cantidad. Son llamados por los turcos L'Andalusin y no pueden ser soldados ni pajes, esto es, gozar paga, ni ascender a ningún cargo honorable, sino que

2. Sobre Busbeken, ver M.A. de BUNES, La imagen de los musulmanes y del norte de África en la España de los siglos XVI y XVII. Los caracteres de una hostilidad, Madrid, CSIC, 1989, pp. 6, 49, 167, 246, 287, 303. 
tienen que inclinarse siempre ante los turcos: por eso se dedican, en general, al comercio]

"Die Stadt Thunis

Aber die Mohren / die man aus Granade und Spanien verjaget / haben die Stadt nach der Zeit mit allerhand Künstlern und Handwerkern sehr vermehret / ja den Kauf so hoch gebracht / daß Thunis in allem fast den besten Handelns-Städten in Europa ist gleich worden" (p. 50).

[La ciudad de Túnez

Pero los Moros que han sido echados de Granada y España con el tiempo han hecho prosperar mucho la ciudad con diversos artistas y artesanos, y, además, han revitalizado tanto el comercio que Túnez casi se ha equiparado a las mejores ciudades comerciales en Europa]

"Andulenser in Spanien gekommen

(...) So hat er sie endlich im Jahre 1492 / als solche / die des Mahomets falscher Lehre beyflichteten / mit Gewalt unter seine Bohtmäßigkeit gebracht. Auch musten sie dag Christentum annehmen / welches sie auch thaten / ob zwar nur ihrer etliche dem Scheine nach.

Werden aus Spanien vertrieben

Als sie aber nach der Zeit etwas zum Nachtheile des Königreichs vor hatten / ließ sie König Philipp der III. auf den 26 Neu-Jahres Monden im 1610 Jahre / gantz aus dem Reiche verbannen. Und also machten sich Jung und Alt / bey 1000000 starck / zu Schiffe / und zogen meistentheils nach Africa in der Barberey. Andere begaben sich in die Landstriche umb Constantinopel herumb / da sie den Christen viel Dampffs anthaten. Auch kamen über 150 in Franckreich / da ihnen der König Freyheit zu wohnen vergönnete / doch mit dem Bedinge daß sie sich zur Spanischen Kirche halten und bekennen sollten. Und noch jetzund werden von ihnen noch etliche Hauß=Gesinde in Languedock und Provanz gefunden.

Fliehen nach Salee

Bey dieser Gelegenheit stellten sich gleichfals viele zu Salee ein / da man ihnen eben die Freyheit zuließ / als die eingeborenen Mohren hatten; vielleicht darumb weil sie Mahometaner waren / oder aber / weil der König von Feß und Marock ihm einbildeten / daß seine Unterthanen vieler Künste und Handwercke von ihnen lernen würden / und kauften vor das Geld welches sie mit aus Spanien gebracht / etliche Schiffe und Kriegs=Waffen. Mit diesen Schiffen begaben sie sich in See zu rauben erstlich unter dem Schein / als wenn sie nur allein die Spanischen Schiffe anthaten wollten / wiewohl es hernach alle Christen betraff. Sie fuhren als wenn sie Spanier wären / wie sie 
dann auch in Spanien / geboren und die Sprache konnten / mit spanischen Flaggen / endlich aber / als sie bekandt worden / zogen sie das vermumte Angesicht herunter / und erklärten sie öfentlich vor See=Räubern und Feinde der Christen. Von den Schiffen so sie geraubt / bezahlten sie dem König von Marock eine gewisse Schätzung / und gaben ihm von jedem 100 den zehenden oder siebenden Theil / so wohl von dem Kauf Wahren als Gefangenen. Daher sind dem Könige alle Leibeigene / die er hat / von den Andulensern zugekommen; weil sonst niemand in dem Königreich Feß und Marock Raub=Schiffe ausrüstet / als die von Salee" (76 ss.).

[Andaluces llegados a España

Así se les oprimió por fin con fuerza en el año 1492 como seguidores de la falsa doctrina de Mahoma. También tenían que abrazar la fe cristiana, lo que de hecho hicieron, aunque muchos de ellos solamente en apariencia.

Son expulsados de España

Pero como con el correr del tiempo tenían algo planeado en perjuicio del Reino, el Rey Felipe III les hizo desterrar por completo del reino el 26 de la luna del año nuevo del año 1610. Y así se embarcaron, mozos y viejos, como 1.000.000, y la mayor parte se fue a África en la Berbería. Otros se fueron a las comarcas de Constantinopla, donde ejercieron mucha presión sobre los cristianos. También llegaron más de 150 a Francia porque el Rey les concedió libertad de vivir pero con la condición de que debían observar y reconocer a la Iglesia española. Y allí algunos de ellos se encuentran todavía como criados en Languedoc y Provenza.

Huyen a Salé

Con esta oportunidad aparecieron muchos en Salé porque se les daba así la libertad que tenían los moros nativos; tal vez por eso, porque eran mahometanos, o porque el Rey de Fez y Marruecos se imaginaba que sus súbditos aprenderían de ellos muchas artes y artesanías. Compraron con el dinero que traían de España algunos barcos y armas de guerra. Con estos barcos salían al mar para robar, primero con la excusa de que querían atacar sólo a los barcos españoles, aunque después lo padecieron todos los cristianos. Salían como si fuesen españoles, con banderas españolas, pues habían nacido en España y sabían el idioma, pero al fin, cuando fueron reconocidos, se quitaron la máscara y se declararon públicamente como corsarios y enemigos de los cristianos. De los barcos que robaban pagaban al Rey de Marruecos una cierta tasación y le daban de cada cien una décima o séptima parte, tanto de las mercancías como de los cautivos. Por eso todos los siervos que tiene el Rey son de estos andaluces, porque nadie en el Reino de Fez y Marruecos arma barcos de corso como éstos de Salé]. 


\section{RESUMEN}

Este libro del año 1694 ofrece al lector unas descripciones de las ciudades del corso magrebí, incluyendo informaciones sobre los moriscos en tales lugares. Es un curioso testimonio del siglo XVII que se dirige al público de habla alemana.

\section{ABSTRACT}

This book from 1694 offers the reader some descriptions of the corsair cities in the Maghrib, including varied informations about the moriscos in this places. It is an odd testimony of the XVII century, which is meant for the german public. 